http://jmscr.igmpublication.org/home/ ISSN (e)-2347-176x ISSN (p) 2455-0450 crossref DOI: https://dx.doi.org/10.18535/jmscr/v7i8.12

Journal Of Medical Science And Clinical Research

\title{
Congenital hemidysplasia with ichthyosiform erythroderma and limb defects - A rare entity
}

\author{
Authors \\ Dr Amit Chauhan', Dr Ghanshyam Verma ${ }^{2}$, Dr Geeta Ram Tegta ${ }^{3}$, Dr Pranjal Joshi ${ }^{4}$, \\ Dr Ajeet $\mathrm{Negi}^{5}$ \\ ${ }^{1,4}$ Ex resident, Department of Dermatology, Indira Gandhi Medical College, Shimla, HP \\ ${ }^{2}$ Associate Professor, Department of Dermatology, Indira Gandhi Medical College, Shimla, HP \\ ${ }^{3}$ Professor \& Head of Department, Department of Dermatology, Indira Gandhi Medical College, Shimla, HP \\ ${ }^{5}$ Ex Registrar, Department of Dermatology, Indira Gandhi Medical College, Shimla, HP
}

\section{Introduction}

CHILD Syndrome as proposed by Happle et al. ${ }^{1}$ in 1980 as an acronym to represent a particular phenotype within the heterogenous group of epidermic nevi syndromes characterised by the three main alterations that is Congenital Hemidysplasia, Icthyosiform erythroderma and Limb Defects. Same author, in 1987, replaced the term icthyosiform erythroderma by icthyosiform nevus (CHILD nevus). CHILD syndrome represents a rare multisystemic disorder with only about 60 cases reported in literature till date. ${ }^{2}$ Inherited as X-linked dominant trait, it carries lethality for male embryos. The underlying mutations of the NSDHL gene (NAD[P] H steroid dehydrogenase-like protein) at $\mathrm{Xq} 28$ (Online Mendelian Inheritance in Man300275) involve the cholesterol biosyntheticpathway. ${ }^{3}$ Characteristic clinical features are a peculiar inflammatory skin disorder called CHILD nevus, with aunique lateralization pattern with strictmidline demarcation and ptychotropism (affinity to body folds). ${ }^{4}$ Associated ipsilateral extracutaneous defects in the form of hypoplasia or aplasia may involve the limbsand other skeletal structures, as well as the viscera, such as lung, heart, and kidney. ${ }^{1}$

\section{Case report}

A 12 years old female patient presented with history of difficulty in walking and weakening of left lower limb, inability to bend left knee. There was a discrete erythematous desquamative lesion on left lower limb, left buttock and left vulva, respecting midline, and, in the left axillary region, a well delineated plaque of icthyosiform aspect. Cutaneous examination further revealed an inflammatory nevus involving the left half of the body with yellow-brown, waxy scaling over the left side of the trunk, vulva, perineum, and limbs with sharp midline demarcation.(Figure 1,2) There was involvement of the rim of the pinnae and scalp with sparing of the face. The nevus diffusely involved the anterior thorax and abdomen, but showed a linear arrangement along the lines of Blaschko on the posterolateral thorax and left upper and lower limbs. The ipsilateral foot had anonychia of the 2nd and 4th toes and dystrophy of other nails. Bilateral congenital dislocation of the hip was present. Further examination did not 
show any involvement of other organs such as the eyes, brain, heart, lungs, or kidneys.

A few streaks of involvement on the contralateral side were also present. Ptychotropism in the form of involvement of the flexural creases of the axillae and groin was conspicuous. The left labium majus showed hypertrophy.

Skin biopsy of affected skin from the patient showed features compatible with ichthyosiform dermatosis: acanthosis and extension of rete pegs of the epidermis, marked parakeratotic scaling with loss of the granular layer, occasional clusters of neutrophils, and perivascular and dermal lymphohistiocytic infiltrates, but without the characteristic verruciform xanthoma of CHILD syndrome.(Figure3,4)

A diagnosis of CHILD syndrome was made based upon the clinical and radiological findings. Patient was prescribed topical ketoconazole, twice daily, with antibiotics for secondary infection. There was marked improvement after 3 weeks. She was discharged and advised to continue regular follow up.
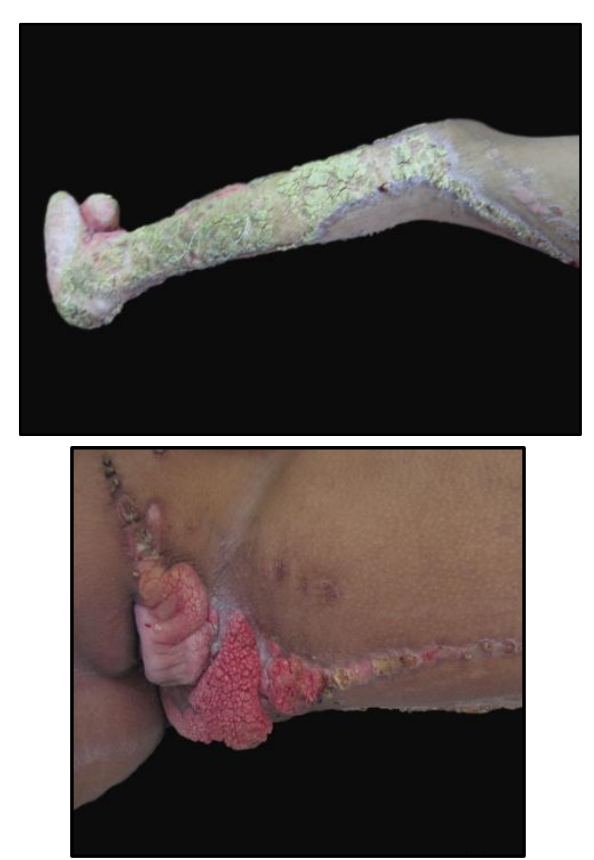

Figure1,2: Crusted, scaly, plaque, blaschoid pattern, Body fold involvement ptychotropism.
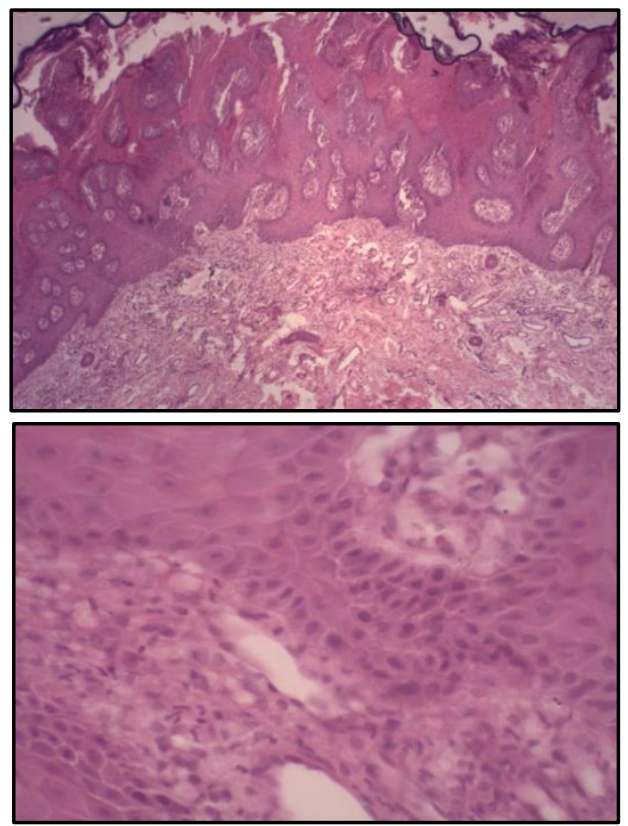

Figure 3,4: Typical psoriasisform epidermis, hyperkeratosis, parakeratosis (100X), Foam cells (400X)

\section{Discussion}

The patient we report here had left sided cutaneous lesions with ipsilateral skeletal defects though CHILD syndrome usually affects the right side of the body. Left sided involvement in this unique pattern of malformation is very rare, reported in only about 20 cases. $^{5}$

In 1992, Emami et al. ${ }^{6}$ proposed a defect in skin fibroblasts resulting in decreased peroxisomes and decreased activity of two enzymes (catalase and dihydroxiacetone-phosphate-acetyltransferase), leading to accumulation of vacuolar structures in these organelles. CHILD syndrome is currently known to be a part of group of diseases caused by enzymatic defects on cholesterol biosynthesis. In 2000, Grange et al. ${ }^{7}$ analyzed plasmatic steroids in patients with CHILD syndrome and suggested that the metabolic defect in CHILD syndrome corresponded to 3-betahydroxisteroid dehydrogenase deficiency (NSDHL). Until now, more than 20 different mutations including missense, nonsense, insertion, deletion, splice site, and silent mutation have been described in the NSDHL gene. ${ }^{8}$

The characteristic lateralization of all defects associated with the CHILD syndrome has been the 
object of debates for representing a specific kind of mosaicism. The specific lateralization pattern probably holds relation to the fact that the origin of a clone of organizing cells coincides with the inactivation of the $\mathrm{X}$ chromosome (lyoniztion) and interferes with it. ${ }^{9,10}$ This organizing cell clone would control a large morphogenetic field, including brain, kidney, half of the heart and bones of one side of the body, which explains the ipsilateral affection of these organs.

Though lethal in male embryos, there are rare case reports of CHILD syndrome in males. ${ }^{11}$ Clinically, the main feature of CHILD syndromeis CHILD nevus, a unilateral, well delineated icthyosifomlesion which respects the midline. It can be present at birth or develop throughout the first years of life, affecting the entire skin of one hemibody, only asegmentor even alternating with bands of normalskin, in a Blaschko line pattern. Regions most commonly affected by CHILD nevus are vulva, armpit and intergluteus sulcus. A review of the syndrome verified the tendency of skin lesions to locate more prominently and persistently in fold areas, characterizing the socalled ptycotropism. Psycotropism is an exclusive characteristic of the CHILD nevus among all other nevi. ${ }^{12}$ Histopathologically, it presents features that resemble psoriasis and xanthoma: alteration ofareas to/from and orthokeratosis, acanthosis, neutro-phils forming microabcesses in the horny layer, but also dermal papillae enlargement due to the presence of histiocytes with cytoplasmaticlipidic deposits. ${ }^{13}$ Still among the cutaneous alterations occurring in this syndrome, a decrease or absence of hairs in amosaic pattern can also occur. Limb defects are ipsilateral to icthyosis and range from digital hypoplasia to complete limb agenesis.

Congenital hemidysplasia can affect skeleton, central nervous, cardiovascular, genitourinary, endocrine and respiratory systems. The most common neurological alterations are ipsilateral hypoplasia of a cerebral hemisphere and/or cranial nerves, EEG alterations and decrease of touch and heat sensitivity. ${ }^{14}$ It is worth highlighting that affected patients usually have normal intelligence. Cardiovascular defects can be lethal, demanding surgical intervention. Other visceral anomalies include ipsilateral absence of a kidney, hydronephrosis and lung hypoplasia.

In the presence of a complete clinical picture, the diagnosis of CHILD syndrome usually offers no difficulties. When only the skin lesion is present, CHILD nevus should be differentiated from Nevil's nevus, linear inflammatory verrucous epidermic nevus, which is more frequent in males, disposed in a linear pattern, with absence of ptycotropism, and with distinguished histopathological features.

Concerning treatment of this syndrome, there isa report of a patient who displayed a great improvement of the cutaneous lesion after the use of acitretin. ${ }^{15}$ Our patient showed marked improvement with the use of topical ketoconazole perhaps because ketoconazole inhibits cholesterol biosynthesis via action on lanosterol $14 \alpha$ demethylase. Treatment with emollients and retinoid scan further provide elief.

\section{References}

1. Happle R, Koch H, Lenz W. The CHILD syndrome: Congenital hemidysplasia with ichtyosiform erythroderma and limb defects. Eur J Pediatr.1980; 134: 27-33.

2. Chander R, Varghese B, Jabeen M, etal. CHILD syndrome with thrombocytosis and congenital dislocation of hip: A case report from India. Dermatology Online Journal 2010; 16(8):6.

3. Caldas H, Herman G. NSDHL, an enzyme involved in cholesterol biosynthesis, traffics through the Golgi and accumulates on ER membranes and on the surface of lipid droplets. Hum Mol Genet 2003; 12(22): 2981-2991.

4. Happle R. Ptychotropism as a Cutaneous feature of the CHILD syndrome. J Am Dermatol1990; 23:763-766.

5. Hummel M, Cunningham D, Mullett CJ, Kelley RI, Herman GE. Left-sided CHILD 
syndrome caused by a nonsense mutation in the NSDHL gene. Am J Med Genet. 2003; 122A (3):246-51.

6. Emani S, Rizzo WB, Hanley KP, Taylor JM, Goldyne ME, Willians ML. Peroxisomal abnormality in fibroblasts from involved shin of CHILD syndrome: Case study and review of peroxisomal disorders in relation to skin disease. Arch Dermatol. 1992; 128: 1213- 22.

7. Grange DK, Kratz LE, Braverman NE, Kelley RI. CHILD syndrome caused by deficiency of 3-beta-hydroxysteroid-delta8, delta-7-isomerase. Am J Med Genet. 2000; 90: 328-35.

8. Bornholdt D, König A, Happle R, Leveleki L, Bittar M, Danarti R, Vahlquist A, Tilgen W, Reinhold U, PoiaresBaptista A, Grosshans E, Vabres P, Niiyama S, Sasaoka K, Tanaka T, Meiss AL, Treadwell PA, Lambert D, Camacho F, Grzeschik KH. Mutational spectrum of NSDHL in CHILD syndrome. J Med Genet. 2005; 42: e17.

9. Happle R, Mittag H, Kuster W. The CHILD nevus: a distinct skin disorder. Dermatology1995; 191: 210-216.

10. Happle R. The group of epidermal nevus syndromes capsule summary. Journal of the American Academy of Dermatology 2010; 63(1):1-22.

11. Bittar M, Happle R, Grzeschik KH. CHILD syndrome in 3 generations. Arch Dermatol. 2006;142(3):348-351.

12. Konig A, Happle R, Fink-Puches R, Soyer HP, Bornholdt D, Engel H, et al. A novel missense mutation of NSDHL in an unusual case of CHILD syndrome showing bilateral, almost symmetric involvement. J Am AcadDermatol. 2002; 46: 594-6.
13. Hebert AA, Esterly NB, Holbrook KA, Hall JC. The CHILD syndrome: histologic and ultrastructural studies. Arch Dermatol. 1987; 123: 503-9.

14. Falek A, Heath CW, Ebbin AJ, McLean WR. Unilateral limb and skin deformities with congenital heart disease in two siblings: A lethal syndrome. J Pediatr. 1968; 73: 910-3.

15. Happle R. Epidermal nevus syndromes. Semin Dermatol. 1995; 14: 111- 21. 